\title{
A Demonstrative GPS-aided Automatic Landslide Monitoring System in Sichuan Province
}

\author{
Pinggen Zhou, Baishen Zhou \\ China Institute of Geo-environmental Monitoring, Beijing, 100081,China \\ e-mail: zhoupg@mail.cigem.gov.cn; Tel:86-10-62179926; Fax: 86-10-62173426 \\ Jingjun Guo, Donghang Li, Zhigang Ding \\ Tsinghua University, Beijing, 100084, China \\ e-mail: lidonghang@tsinghua.org.cn; Tel:86-10-62702528; Fax: 86-10-62702529
}

\author{
Yanming Feng \\ Cooperative Research Centre for Satellite Systems, Queensland University of Technology, GPO 2434,Q4001 \\ e-mail: y.feng@qut.edu.au; Tel:0061-7-38641363; Fax: 0061-7-38641517
}

Received: 15 November 2004 / Accepted: 12 July 2005

\begin{abstract}
In China, the geological disasters of landslide and mud-rock flows cause losses of over 1000 lives and total economic losses of over 10 billions of RMB each year. There have been about 90,000 identified landslide sites, mostly distributed in several southern and northwestern provinces of China. In the reservoir area of the Three-Gorge project only, over 1000 landslide sides have been identified. A joint research was launched involving authors from a number of scientific institutions to explore technologies and methodologies for landslide monitoring with focus on the characteristics of the geological disasters at the up and middle reaches of Yangtze River. This paper studies the combined technologies for landslides monitoring and presents a demonstrative automatic landslide monitoring system in a chosen ancient landslide site, where the creeping movement process continues since its latest large sliding on August 25,1981 . The landslide test-bed is $500 \mathrm{~m}$ long and $300 \mathrm{~m}$ wide located in the Ya'an-Xiakou area in Sichuan province. To study the mechanism of the sliding process, 15 permanent GPS monuments were built in the area for regular observations. Automatic ombrometers, digital thermometers, underground water-level-meter and ground fissure-displacement-meter were set-up as well. The data from these automatic sensors are collected and automatically sent to the data process centre in Beijing via the Beidou-1 communication satellite. The paper also compares the landslide results from three GPS observing campaigns, demonstrates the feasibility to identify the displacements at the accuracy level of $2 \mathrm{~mm}$ using the dual-frequency GPS receivers. The results are
\end{abstract}

encouraging and further analyses will be conducted, considering influences of non-GPS measurements.

Key words: Augmented Reality, GPS, Inertial Sensors, Kalman Filter, Integrated Systems

\section{Introduction}

China is a country frequently suffered from various geological hazards. With the boom of economy and a great deal of ongoing engineering projects such as transportation, water conservancy and resource development, as well as the influence of environmental changes, damages caused by landslide are sharply increasing. According to Tang (2004), in recent years, rock falls, landslide and debris flow have caused an economic loss of about 10 billion RMB and over 1000 lives per annum. In China, about 700 Counties (local governments) have suffered from geologic hazards for long and tens of millions of residents living in these areas face threatens of serious geologic hazards, but lack of a sense of safety. This sometimes causes serious social problems. Therefore, it is particularly important to develop cost-effective reliable landslide monitoring systems and technologies.

Landslide monitoring is a complex of technological means. Deformation monitoring is one of the most 
important parts, providing an important basis for identifying landslide. Conventional geodetic surveying methods for deformation monitoring include transit traverse survey, triangulation method, levelling survey, total station methods. These methods provide reasonable accuracy, but requiring skilled professionals to conduct the work in situ, resulting in heavy workload, high personnel risk and low efficiency. Monitoring and timely alarms in case of hazard cannot be realized at night or in continuous rain. Use of GPS can improve the situations considerably (Xu et al, 2003, Xu et al.,2003, Gili and Corominas, 2000). First, GPS can operate in all-weather conditions and inter-station visibility is not required; second, GPS static relative positioning can achieve millimetre accuracy to meet the requirements (Guo et al, 2004 and Zhao et al, 2001). Third, if the satellite communication is available to transfer the observation data from the remote site lacking of landline communication to an urban data processing centre, thus realizing automatic monitoring is more feasible.

Addressing the characteristics of geologic hazards in the middle and upper reach of Yangtze River in China, China Institute of Geo-Environment Monitoring and Tsinghua University jointly constructed GPS-based landslide monitoring demonstrative network at the Ya'an-Xiakou landslide site in Sichuan Province. Regular monitoring results since 2003 have demonstrated that GPS can provide required accuracy for landslide monitoring in the demonstrative case, which can lead to completely replacing conventional geodetic surveying instruments, showing also advantages in terms of speed and efficiency (Guo et al, 2004). The test-bed is also equipped other monitoring devices such as automatic pluviometer, digital thermometer, underground water gauge and geofracture displacement meter, to form a complete set of automatic landslide monitoring system. All the monitoring data are transmitted to Beijing Monitoring Analysis Centre through the China Beidou No 1 navigation/satellite communication channel. The system is 24/7 automatic unmanned monitoring system.

\section{GPS landslide monitoring experiments and results}

\subsection{Description of the experimental landslide area}

As shown in Figure 1, the Ya'an- Xiakou, also called Wujia Mountain, landslideis situated in the east bank of the gorge in the middle reaches of Longxi River in Longxi Village, north of Ya'an City, Sichuan Province. It is the largest landslide in the local area. The whole landslide area consists of an ancient rock fall and landslide deposit of about 10 million M2. (unknown time), a reactivation landslide of 2.60 million M2 (1981) as well as a deformable body of 0.75 million M2 (the part deformed in late 1990s after sliding in 1981). Overall sliding is direction I is from East to West. The sliding mass is the ancient rock fall deposit, gravel mixed with mauve clay, and the stone's diameter is 0.2 to $2 \mathrm{~m}$. The sliding mass features favourable conditions for influent seepage and shallow layer of underground water. The region enjoys warm and wet climate, and that is why Ya'an is also called Rain City. The mean annual temperature there is $16^{\circ} \mathrm{C}$, and the annual rainfall is $1,800 \mathrm{~mm}$, mostly in the season June to September.

On the night of August 19th, 1981, a storm broke out, and a large amount of rain flowed into the slope, triggering off a large-scale slide and resulting in collapse of houses and ruin of roads and channels. Different degrees of deformation occurred in the creep deformation body of the reactivation landslide following the rain season in 1995, and formed a potential sliding mass(Zhao). Experimental area is located at the reactivation body, $500 \mathrm{~m}$ long and $300 \mathrm{~m}$ wide, running from east to west slightly southwards about $25.50^{\circ}$.

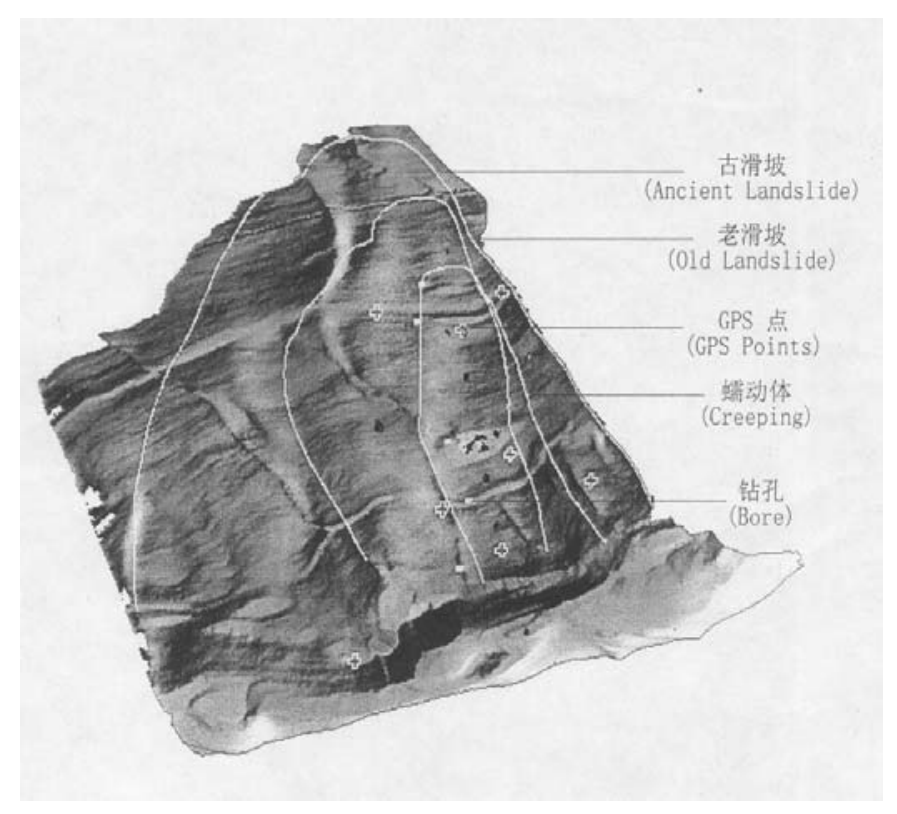

Fig. 1 Sliding mass at the Xiakou landslide 2.1 Reference Frames

\subsection{Ya’an-Xiakou GPS landslide monitoring network}

Reference points. Two points at the stable rock mass outside the sliding mass were chosen as reference sites. One is in the east and the other is in the northern ridge, numbered as ya15 and ya17, respectively

Monitoring points. We set up monitoring points according to the features of the local sliding mass. These points should reflect the general deformation direction of the sliding mass, magnitude of the deformation, as well as range of the sliding mass and deformation speed. Reception of signals from the satellite was considered at 
each point. There should be no large-area screening objects over the monitoring point (Liu et al., 1996). There are in total fifteen monitoring points placed in the test area, of which there are five points placed from top to bottom crossing the section of landslide, each being close to the inclinometer and crack displacement measuring device. Three monitoring points are set up next to the pluviometer and the underground water level measuring device. The remaining seven points are scattered around the sliding mass. The average distance between the points is $120 \mathrm{~m}$, with the maximum of $229 \mathrm{~m}$ and the minimum of $17 \mathrm{~m}$. At each monitoring point, the GPS monument was cast with reinforced concrete with $1.5 \mathrm{~m}$ underneath, and $1.5 \mathrm{~m}$ above the ground. A forced centring device is also placed on the top of the observation pillar. Figure 2 illustrates the layout of the monitoring points of the GPS network.

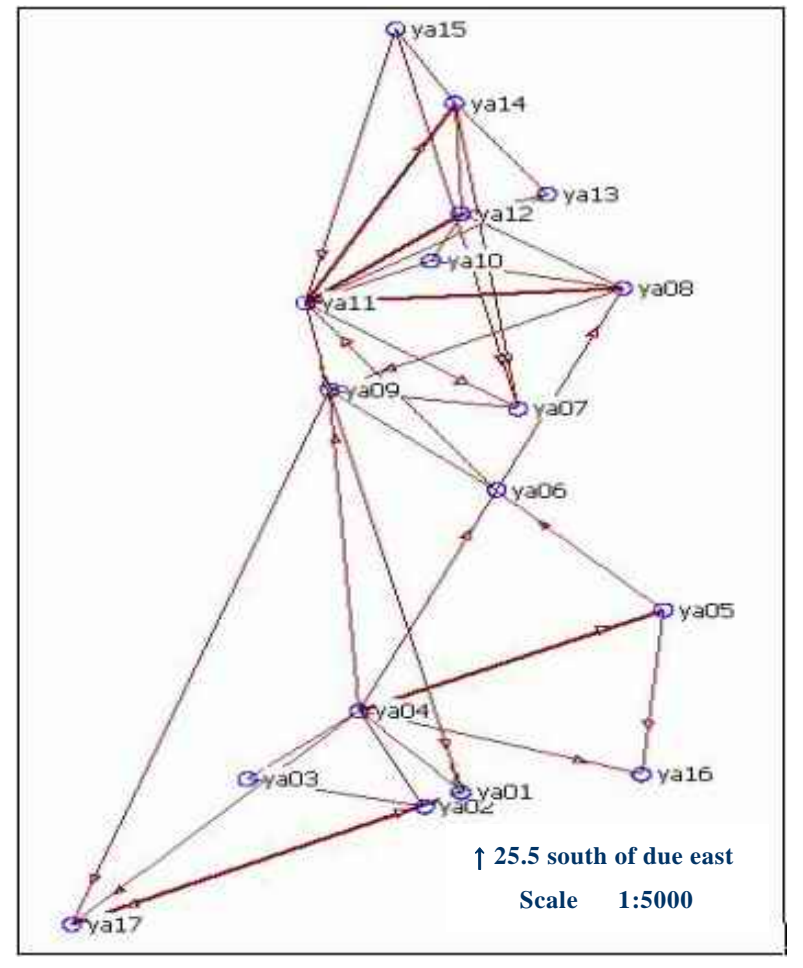

Fig. 2 Layout of GPS observation points

\subsection{Collection and processing of GPS data}

Four Novatel PROPAK-II-TR2 dual-frequency GPS receivers were used for GPS data collection and observation conducted in March and October of 2003 in the area. The data collection with a PDA-based device developed by the researchers from Tsinghua University GPS data were recorded at 5 seconds interval with 1 hour session length. The elevation cut-off angle of $10^{\circ}$ was set. Meanwhile, Activesync software was used to enable PDA and computer communication. The observation data were converted to the standard RINEX format for processing.
The baseline positioning was completed using Trimble Geomatics Office software. The results show the maximum RMS values of $8 \mathrm{~mm}$, the minimum value of 2 $\mathrm{mm}$ and the average value of $3.4 \mathrm{~mm}$. 2.2.1 Kalman filter functional model for the GPS observations

\subsection{Results and Analysis}

\section{Baseline consistency check}

To ensure accuracy of the observation results, in each round of experiments, several baselines were observed twice, allowing to conduct internal consistence checks between the solutions. Table 1 gives the results from the test conducted in March 2003. As seen, the maximum difference between the two baseline solutions is $4 \mathrm{~mm}$, while the RMS is $3 \mathrm{~mm}$ for all the baselines.

Tab. 1 Baseline consistency Check

\begin{tabular}{|l|l|l|l|l|l|}
\hline From & To & $\begin{array}{l}\text { Baseline } \\
\text { length } \\
(\mathrm{m})\end{array}$ & $\begin{array}{c}\text { Computation } \\
\text { method }\end{array}$ & Ratio & $\begin{array}{c}\text { RMS } \\
(\mathrm{m})\end{array}$ \\
\hline ya04 & ya05 & 142.184 & L1 fixed & 4.5 & .003 \\
\hline ya04 & ya05 & 142.188 & L1 fixed & 5.7 & .003 \\
\hline ya08 & ya11 & 136.728 & L1 fixed & 23.5 & .003 \\
\hline ya08 & ya11 & 136.732 & L1 fixed & 53.6 & .003 \\
\hline ya11 & ya12 & 84.006 & L1 fixed & 22.2 & .003 \\
\hline ya11 & ya12 & 84.003 & L1 fixed & 31.8 & .003 \\
\hline ya11 & ya14 & 133.899 & L1 fixed & 11.4 & .003 \\
\hline ya11 & ya14 & 133.899 & L1 fixed & 33.2 & .002 \\
\hline
\end{tabular}

\section{Close- loop consistence checks}

The zero theoretical value for sum of the coordinate differences in a loop formed by three or more baseline vectors can be used to check the results as well. Referring to Figure 2, each triangle in the network can form a close loop. There are totally 40 close loops, of which 39 passed the test. The failed one related to the monitoring point ya06, which is close to a house and same threes. The quality of GPS signals might be affected.

\section{GPS network adjustment}

The baseline solutions from the test in March 2003 was adjusted using rank defect free network adjustment (Cui et al., 2000). Table 2 shows the positional RMS accuracy of the network adjustment results.

\section{Gauss projection}

To minimize the deformation of the coordinates in the landslide monitoring, Gauss map projection is made at the arbitrary zone closest to the survey area. That is, the longitude $103^{\circ} 01^{\prime} \mathrm{E}$ is taken as the central meridian and projection is made at north latitude $30^{\circ}$ as latitude of pedal with the projection height of $820 \mathrm{~m}$ (geodetic height), thus minimizing the projection error and ensuring 
that the projection error will not affect the accuracy of monitoring. To ensure that $\mathrm{Y}$ coordinate is the positive one, we moved $\mathrm{Y}$ coordinate eastwards to the longitude $103^{\circ} \mathrm{E}$. Table 3 gives the coordinate projection results.

Tab. 2 Positional accuracy after network adjustment process

\begin{tabular}{|c|c|c|}
\hline Points & $\begin{array}{c}\text { Error in vertical } \\
\text { axis }(\mathrm{m})\end{array}$ & $\begin{array}{c}\text { Error in horizontal } \\
\text { axis }(\mathrm{m})\end{array}$ \\
\hline Ya01 & 0.009 & 0.004 \\
\hline Ya02 & 0.003 & 0.002 \\
\hline Ya03 & 0.003 & 0.003 \\
\hline ya04 & 0.002 & 0.002 \\
\hline ya05 & 0.003 & 0.002 \\
\hline ya06 & 0.003 & 0.003 \\
\hline ya07 & 0.002 & 0.002 \\
\hline ya08 & 0.002 & 0.002 \\
\hline ya09 & 0.002 & 0.001 \\
\hline ya10 & 0.003 & 0.002 \\
\hline ya11 & 0.002 & 0.002 \\
\hline ya12 & 0.002 & 0.002 \\
\hline ya13 & 0.002 & 0.003 \\
\hline ya14 & 0.002 & 0.002 \\
\hline ya15 & 0.003 & 0.003 \\
\hline ya16 & 0.003 & 0.003 \\
\hline ya17 & 0.002 & 0.002 \\
\hline Maximum & 0.009 & 0.004 \\
\hline Minimum & 0.002 & 0.001 \\
\hline Average & 0.003 & 0.002 \\
\hline
\end{tabular}

Tab. 3 Results of Gauss Map Projection

\begin{tabular}{|l|c|c|c|c|}
\hline Points & $\begin{array}{c}\text { North } \\
\text { coordinate } \\
(\mathrm{m})\end{array}$ & $\begin{array}{c}\text { Error in } \\
\text { vertical } \\
\text { axis }(\mathrm{m})\end{array}$ & $\begin{array}{c}\text { East } \\
\text { coordinate } \\
(\mathrm{m})\end{array}$ & $\begin{array}{c}\text { Error in } \\
\text { horizontal } \\
\text { axis }(\mathrm{m})\end{array}$ \\
\hline ya01 & 7840.813 & 0.009 & 1463.268 & 0.004 \\
\hline ya02 & 7858.419 & 0.003 & 1462.534 & 0.002 \\
\hline ya03 & 7920.010 & 0.003 & 1509.314 & 0.003 \\
\hline ya04 & 7860.236 & 0.002 & 1523.291 & 0.002 \\
\hline ya05 & 7718.432 & 0.003 & 1519.071 & 0.002 \\
\hline ya06 & 7753.409 & 0.003 & 1610.950 & 0.003 \\
\hline ya07 & 7725.563 & 0.002 & 1648.389 & 0.002 \\
\hline ya08 & 7656.025 & 0.002 & 1690.707 & 0.002 \\
\hline ya09 & 7793.487 & 0.002 & 1692.598 & 0.001 \\
\hline ya10 & 7723.173 & 0.003 & 1739.654 & 0.002 \\
\hline ya11 & 7781.867 & 0.002 & 1741.487 & 0.002 \\
\hline ya12 & 7700.098 & 0.002 & 1758.348 & 0.002 \\
\hline ya13 & 7662.237 & 0.002 & 1752.438 & 0.003 \\
\hline ya14 & 7675.655 & 0.002 & 1815.950 & 0.002 \\
\hline ya15 & 7680.316 & 0.003 & 1864.527 & 0.003 \\
\hline ya16 & 7767.043 & 0.003 & 1439.250 & 0.003 \\
\hline ya17 & 8022.828 & 0.002 & 1467.256 & 0.002 \\
\hline
\end{tabular}

\section{Conversion of coordinates}

To facilitate analysis on the sliding mass, we convert the gauss projection coordinates to rectangular coordinate system at the sliding mass direction. The main sliding mass direction ya01-to-ya12 is the negative direction for $\mathrm{X}$ - axis, and $\mathrm{Y}$ - axis is normal to $\mathrm{X}$ - axis to form the right hand rectangular coordinate system. Table gives the coordinates of each point after the coordinate conversion.

Tab. 4 Results of Coordinate Conversion

\begin{tabular}{|c|c|c|}
\hline Points & $\begin{array}{c}\text { X after conversion } \\
(\mathrm{m})\end{array}$ & $\begin{array}{c}\text { Y after conversion } \\
(\mathrm{m})\end{array}$ \\
\hline ya01 & 917.109 & 846.902 \\
\hline ya02 & 908.869 & 831.326 \\
\hline ya03 & 924.583 & 755.597 \\
\hline ya04 & 962.927 & 803.534 \\
\hline ya05 & 1020.155 & 933.346 \\
\hline ya06 & 1088.032 & 862.227 \\
\hline ya07 & 1133.811 & 871.246 \\
\hline ya08 & 1201.940 & 915.798 \\
\hline ya09 & 1144.478 & 790.908 \\
\hline ya10 & 1217.218 & 834.120 \\
\hline ya11 & 1193.608 & 780.353 \\
\hline ya12 & 1244.024 & 846.902 \\
\hline ya13 & 1254.986 & 883.620 \\
\hline ya14 & 1306.538 & 844.170 \\
\hline ya16 & 927.183 & 923.826 \\
\hline ya17 & 842.364 & 680.894 \\
\hline
\end{tabular}

Table 4 gives the results from the experiment conducted in March 2003. The second experiment took place in October. The same observation methods and data processing strategies were taken as in March 2003, but the coordinates of the reference point ya15 known from the pervious time were used in the network adjustment. In addition, no observation was taken for Point ya07, due to the complete blockage of signals by crops. 
Tab. 5 Displacement of points

\begin{tabular}{|l|c|c|}
\hline & $\mathrm{dx}(\mathrm{m})$ & $\mathrm{dy}(\mathrm{m})$ \\
\hline YA01 & -0.040 & -0.001 \\
\hline YA02 & -0.031 & 0.008 \\
\hline YA03 & -0.042 & 0.000 \\
\hline YA04 & -0.042 & -0.003 \\
\hline YA05 & -0.028 & 0.016 \\
\hline YA06 & -0.027 & -0.008 \\
\hline YA08 & -0.012 & 0.015 \\
\hline YA09 & -0.042 & -0.003 \\
\hline YA10 & -0.025 & -0.005 \\
\hline YA11 & -0.021 & -0.014 \\
\hline YA12 & -0.015 & 0.004 \\
\hline YA13 & -0.017 & 0.010 \\
\hline YA14 & -0.003 & -0.012 \\
\hline YA15 & 0.000 & 0.000 \\
\hline YA16 & 0.008 & -0.002 \\
\hline YA17 & -0.032 & 0.001 \\
\hline
\end{tabular}

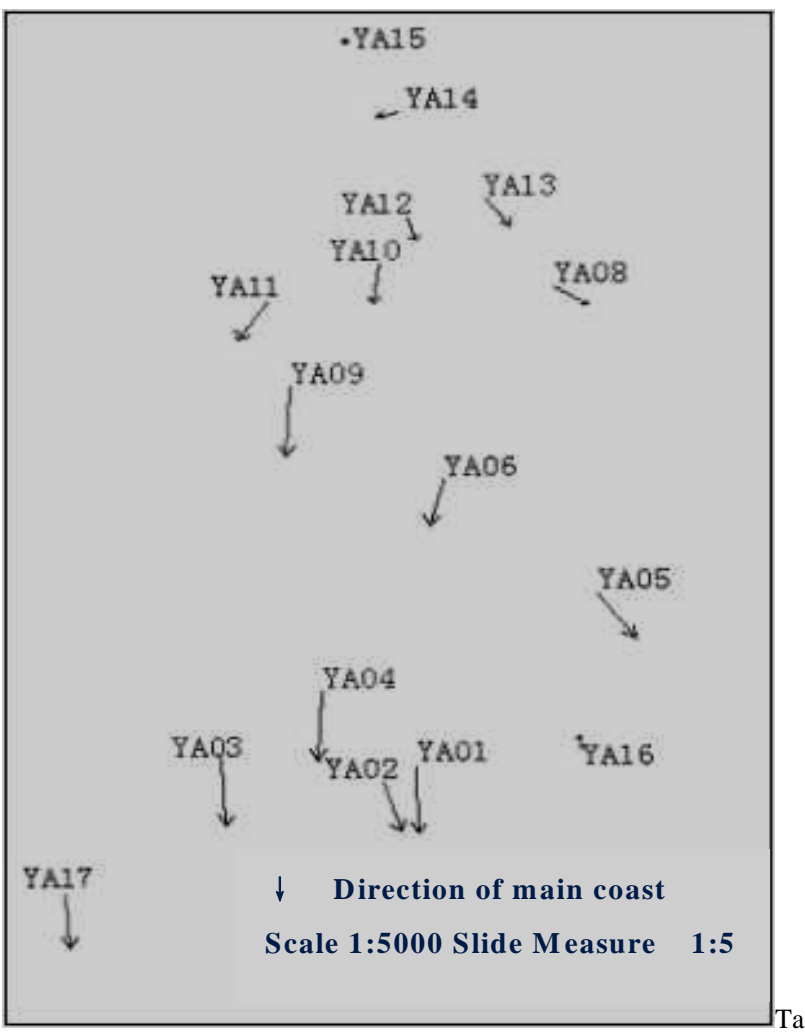

Fig. 3 Map of points displacement
In Table 5, Dx and Dy are the coordinates differences between two experiments for $\mathrm{x}$ and $\mathrm{y}$ components, respectively.

As seen from Table 5 and Figure 3, sliding mass not only moves along the main sliding direction of the landslide, but in the direction normal to the main sliding direction. This is because the sliding mass projects in the middle, and sinks at the two sides. Results from GPS landslide monitoring accurately reflect sliding tendency and displacement of the sliding.

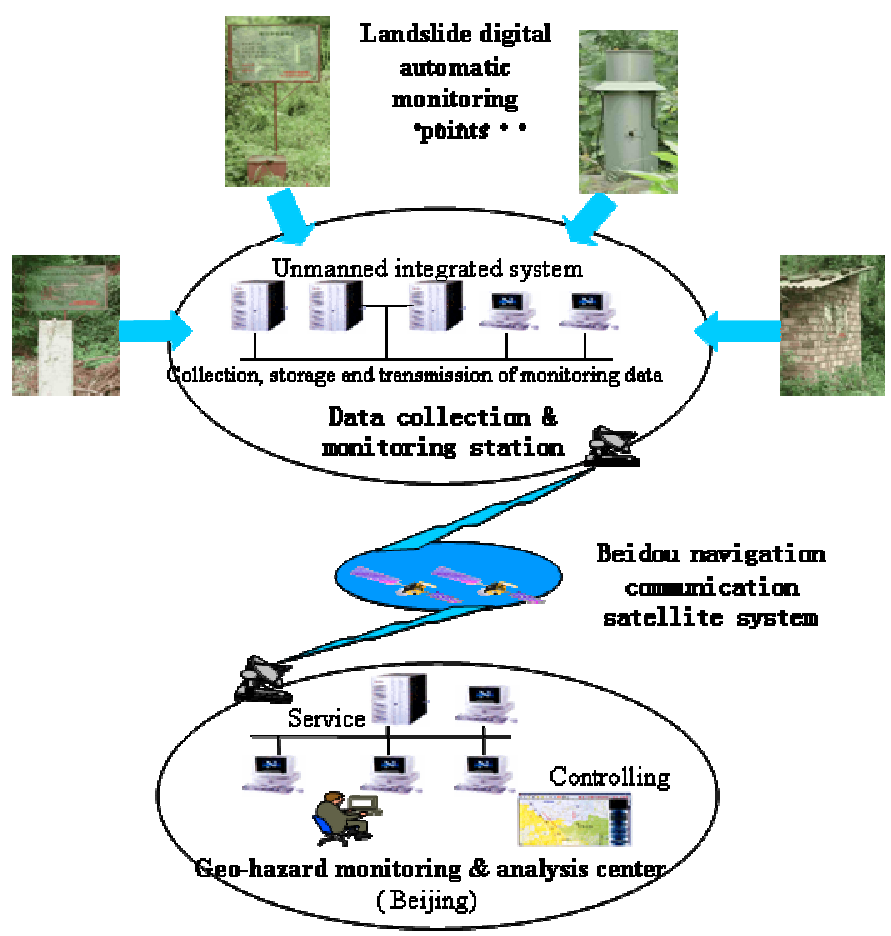

Fig. 4 Composition of landslide remote monitoring system

\section{An automatic landslide monitoring system remotely controlled though Beidou-1 communication satellite}

\subsection{Components of the system}

As shown in Figure 4, the remotely controllable automatic landslide monitoring system, built in the Ya'an landslide area, has four major components: in-field data collection \& monitoring station, digital automatic landslide monitoring point, Beidou-1 navigation satellite communication system and "geologic hazard monitoring \& analysis center”. Detailed descriptions are given as follows.

\section{(1) Field data collection \& monitoring station}

The field data collection \& monitoring station is a set of unmanned integrated data collection system. It includes an information monitoring and collection platform for various geological measurements, such as absolute 
displacement monitoring for landslide ground, monitoring for displacement of the deeper parts of the landslide, dynamic monitoring for landslide underground water, landslide relative displacement monitoring, and monitoring for inducing factors of landslide. These elements are consolidated and integrated into one unit to collect, store, compress and transfer various data. Figure 5 is the integrated rack.

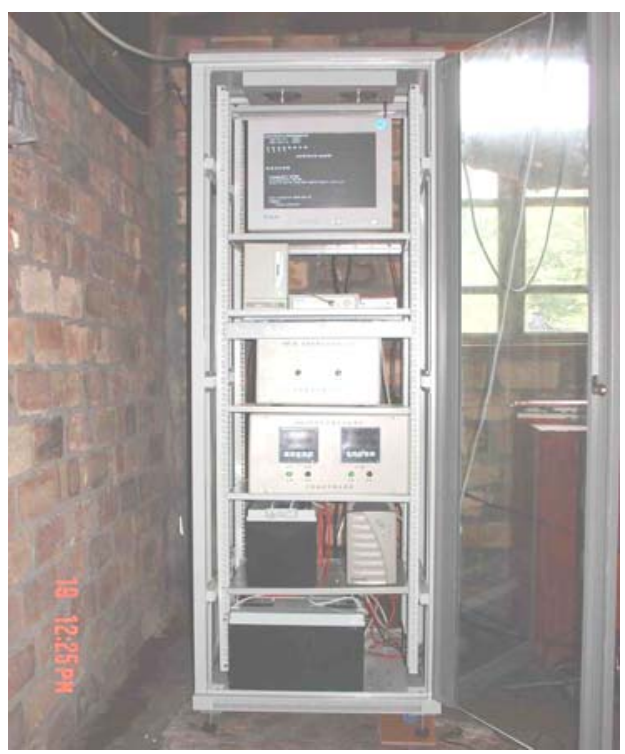

Fig. 5 Field data collection \& monitoring station

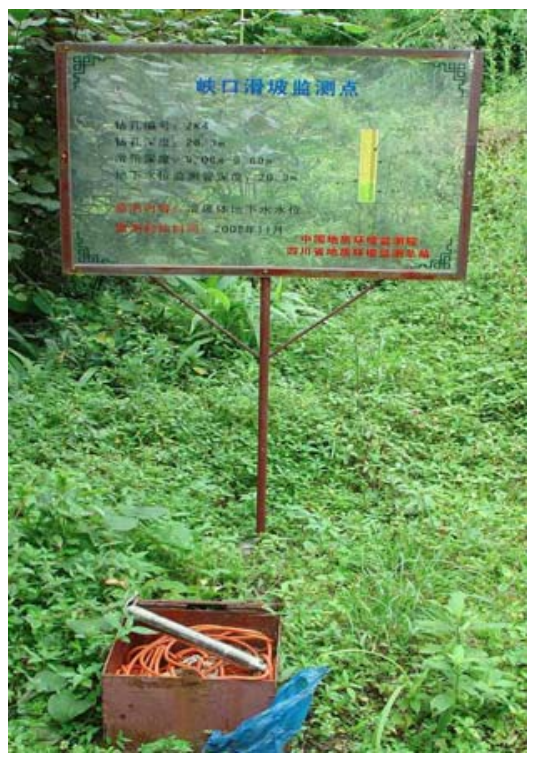

Fig. 6 Underground water level monitoring point

\section{(2) Digital automatic landslide monitoring points}

These digital automatic landslide monitoring points are scattered everywhere in the landslide area in order to use various digital monitoring methods to collect data concerning the geological environmental parameters, such as underground water level, water temperature, rainfall, displacement of the earth surface, deformation of deeper parts and so on. The monitoring devices include borehole tiltmeter, geofracture displacement meter, digital automatic pluviometer, automatic water level meter and so on. Figure 6 indicate one of the monitoring points-underground water level monitoring point.

(3) Beidou-1 navigation/ communication satellite system "Beidou-1 navigation communication satellite system"is a regional navigation system in China. It can provide allweather, around-clock satellite navigation information, time service and two-way communication service (Ha, 2004). Communication signal of this system is stable, and high intensively encrypted measures are designed to ensure security and reliability, so it is very suitable for monitoring landslide hazard in harsh and complicated field conditions. This system is composed of space segment, a ground controlling center and Beidou-1 user terminal. Figure 7 illustrates the concept of the Beidou-1 system and services.

The space segment of Beidou-1 navigation communication satellite system includes two earth synchronous orbit satellites (GEO), namely BDSTAR-1 and BDSTAR-2. The signal transmission device on the satellite is available to complete the relay task for twoway wireless signals between ground controlling central station and the client terminal.

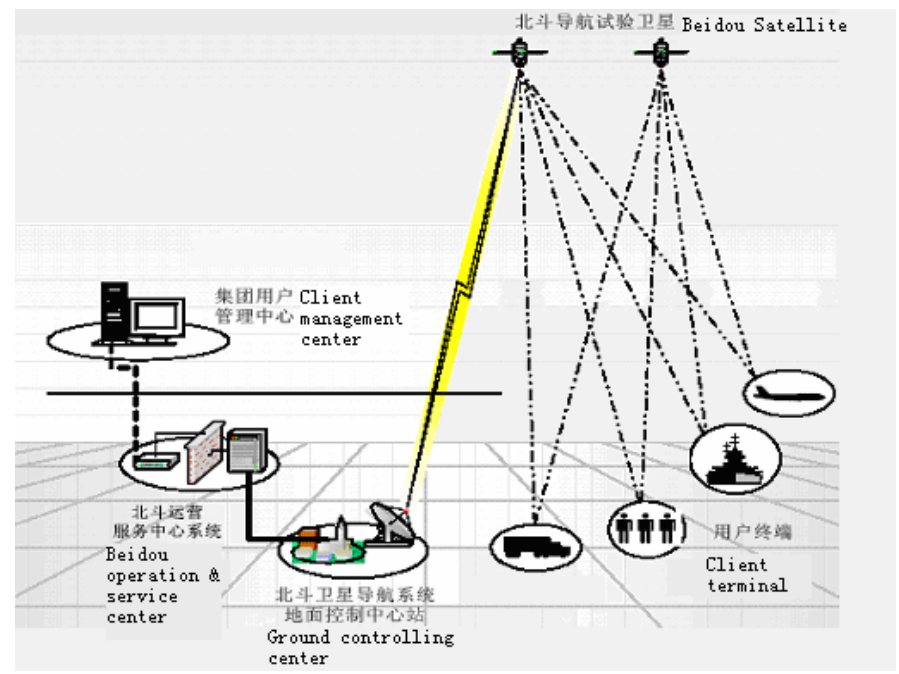

Fig. 7 Diagram for comprehensive information service structure of Beidou-1 navigation communication satellite system

(4) Geologic hazard monitoring \& analysis center The geologic hazard monitoring \& analysis center comprises a Beidou-1 communication user receiver, a database server and an analysis unit. In terms of its functions, the system includes the controlling software for landslide remote monitoring system operation a database and monitoring data analysis software. Through Beidou-1 communication client receiver, the center uses satellite signal channel to receive data collected and sent from the field, and process and store the data and results in the database server. The system controlling software can automatically feed back information, and meanwhile 
telecontrol field data collection \& monitoring station according to users' requirements for field data collection. The data analysis software can read data from the database any time, analyse and process the data collected, obtain the changing and alarm information of geologic feature, and thus providing valuable reference to the researchers and identifying landslide hazard, and make accurate early-warning. Figure 8 shows the components of the experimental system for monitoring and analysis center.

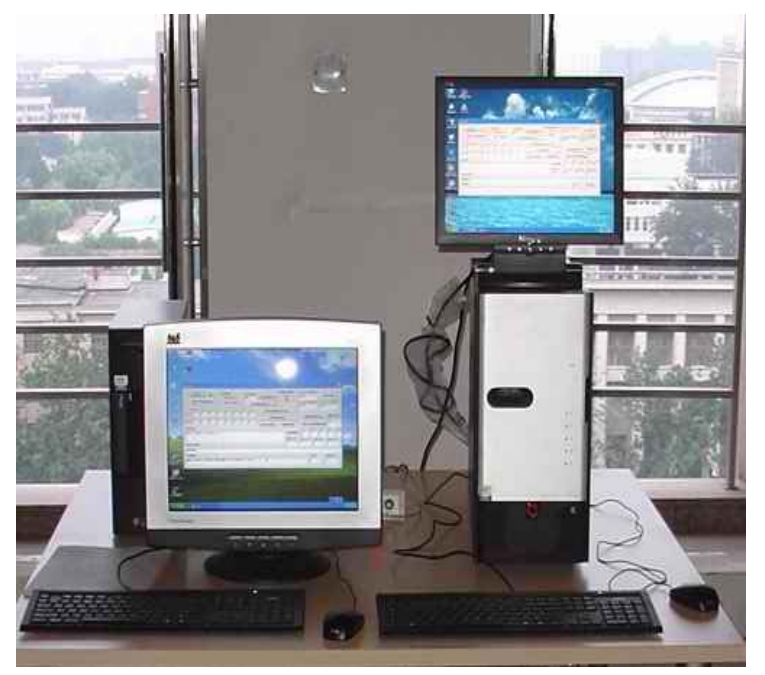

Figure 8. Geo-hazard monitoring \& analysis system (experimental center)

\subsection{Operation and monitoring function of the system}

The remote automatic landslide monitoring system, based on Beidou-1satellite communication, operates as follows:

(1) Field data collection, storage and processing of the geological environmental features, including underground water level, water temperature, rainfall, the earth's surface displacement, deformation of the deeper parts collected by the various digital automatic landslide monitoring points scattering in the landslide monitoring region;

(2) Regular data packaging and compression, or via telecontrol according to the needs, using the transmission and communication function of Beidou-1 satellite navigation system to directly send the data to the geologic hazard monitoring \& analysis center, where the data are analyzed and processed. Meanwhile it can send feedback information and control instructions to the field system through Beidou-1 system as well.

The system enables the center facility to complete the remote monitoring and control over the landslide monitoring sensor through Beidou-1 satellite communication link; while the landslide monitoring sensor regularly transmits the data processed primarily and locally stored by the field data collection \& monitoring station to the central facility. The system is also equipped with satellite communication receiver for cross checking and mutual checking. It can also display the sensor status, check the sensor data; query the current record file in the monitoring station, request for sending the data on the specified date and time, request for sending all the data of designated file, telecontrol running of the monitoring station from the starting point, display in real time the sensor data; time mark, the received data; display the particular running status of the program the instructions ID length of received information; telecontrol the normal exit (save the setting of the current state) and cancellation of the program (exit of the program without change of the original state). Meanwhile the central facility has the capacity of automatically processing remote monitoring data and publicizing the early-warning information promptly.

\section{Conclusions}

GPS monitoring experiment results from the Ya'anXiakou testbed have demonstrated that GPS can provide sufficient accuracy to meet landslide displacement monitoring requirements, leading to the replacement of the conventional geodetic surveying methods. Use of GPS-based methods can significantly improve the efficiency of landslide monitoring and reduce the work intensity of labour. In addition, with means of the Beidou-1 satellite communication system, remote automatic monitoring of the landslide becomes feasible. The demonstrative GPS-aided automatic landslide monitoring system developed has performed well, providing an excellent technological platform for the academics and experts engaged in the research of geological and environmental hazards to timely, accurately and conveniently obtain the real-time monitoring data at each dangerous landslide region. As a result, it saves costs for labour and data acquisition in filed and avoid potential hazard to personnel in the field. Meanwhile, the comprehensive information volume obtained through the system is far greater than the effective data obtained through the conventional means. Moreover, a database with rich and detailed resources can be set up, which would be of great significance to the landslide hazard investigation analysis, forecast, earlywarning and hazard mechanism research in the future.

\section{ACKNOWLEDGEMENTS}

This work was carried out with financial support from the Ministry of Science and Technology (MOST, P. R. China and partially from Australia-China Special Funds for Scientific and Technological Cooperation bilaterally 
offered by MOST and Department of Education, Sciences and Technology (DEST), Australia.

\section{References}

Yin Y. (2004): Initial study on the hazard-relief strategy of geological hazard in China, The Chinese Journal of Geological Hazard and Control, 15 (1): 1-8

Zhou P. (2004): Indicators and techniques of landslide monitoring, Journal of Geomechanics (in Chinese), 10(1):19-26

Xu, S, W. Cheng, X. Huang, D. Xu (2003): The investigation of landslide monitoring in the Three Gorges Reservoir region by applying GPS, Journal of Hydraulic Engineering (in Chinese). (1):114-118

Gili J.A.; Corominas J. (2000): Using Global Position System techniques in landslide monitoring, Engineering Geology (special issue), 55:167-192
Guo J J.; Yang Z.; Ding P.; Zhou X Zhu. (2004): Application of GPS on landslide monitoring-A case study of Xiakou landslide, Journal of Geomechanics (in Chinese). 10(1): 63-70

Zhao Y. (2001): Mechanical analysis of sliding process of Ya'an Xiakou landslide and prediction of its hazard model, Journal of Engineering Geology(in Chinese). 9(2): 188-193

Liu, D Y Shi, J Guo (1996): The Elements and Data Processing of Global Position System, Tongji University Press, Shanghai

X Cui, Z Yu, B. Tao (2000): The Generalized Surveying Adjustment, Survey and Mapping Press, Beijing

Ha B. (2004) Beidou Navigation and Position Satellites System, China Metrology,(3):22-23 